\title{
Research on Hot Topics and Frontier Analysis of Enterprise Financial Pressure
}

\author{
Wang Shujun \\ Business School, Sichuan University \\ Chengdu, China
}

\begin{abstract}
This paper reviews existing literature on enterprise financial pressure and hopes to provide corresponding support for the follow-up research based on the comprehensive summary of domestic and foreign literature relevant to enterprise financial pressure. Using inductive method, this paper discusses the concept, theoretical basis, basic framework and influence of enterprise financial pressure. This paper finds that the issue of enterprise financial pressure is still an embryonic concept, and there has not been a generally accepted definition. The findings prove that enterprise financial pressure is not only the hot topic and also the new field, which may be the research trend in the future.
\end{abstract}

Keywords-financial pressure; enterprise; financial risk; financial management

\section{INTRODUCTION}

There is an intense competition among enterprises under the current socialist market economy system. Financial management is essential to invigorate funds, enhance financial liquidity as well as soundness to ensure the stability and development of enterprises. The cost pressure brought by the debt management mode is increasing day by day and the financial pressure is prominent especially after the mode has been widely adopted by Chinese enterprises, which poses a serious challenge to the financial management of enterprises. How to realize the balance of debts, control pressure and ensure financial flexibility is also an important topic worth considering at present. Financial pressure is occasionally involved in the research of scholars at home and abroad, while there is no systematic and specialized research on financial pressure, mainly because the financial system of enterprises is too complex, quality of the financial situation, the degree of financial pressure and influence is unmeasurable. Therefore, this paper tries to sort out the existing financial pressure related literature at home and abroad for the sake of offering the support for subsequent research.

\section{THE CONCEPT OF FINANCIAL PRESSURE}

At present, financial pressure in the academic community is rarely studied, which is the concept of the prototype. When it comes to "pressure", the first thing that can be thought of is the physics concept of the force that occurs when two objects come into contact with the surface, or the vertical force of a gas to the surface of a solid and a liquid, or a vertical force of a liquid to a solid surface. Except the physics, psychology also has the concept of "pressure", which means that a person's inner conflict and its accompanying strong emotional experience. Duan Huayou (2013) explains the financial pressure of enterprises by having the loan of using the concept of pressure in psychology and physics. In his opinion, the financial pressure is formed by the external environment and internal environment of the enterprise, that is, the financial activities of the enterprise must bear the pressure. This kind of force will have the influence on the financial activities and business activities of the enterprise to a certain extent. At the same time, the force will also create a certain degree of psychological pressure to the management authorities, especially the business managers.

However, Wu Guoping and Zhu Jun (2009) point out that in essence, financial pressure is the behavior of the company from a financial perspective. Typical financial pressures include debt service pressure caused by high debt, cash flow pressure caused by insufficient cash flow, shell protection pressure, surplus protection pressure and signal pressure caused by profitability. Moreover, they reveal that the direct cause of financial report fraud is the huge financial pressure faced by listed companies from both pressure and opportunity.

Gan Shengdao (2016) starts with the sources and objects of financial pressure. He thinks that financial pressure of enterprises is the force caused by the more difficult financial and non-financial indicators imposed by the pressurizer (mostly shareholders) on the pressurizer (business operators). If these indicators can be easily completed, there is no financial pressure on the operators. The greater the difficulty of completion, the higher the financial pressure on the operator, that is, the difficulty of index completion is proportional to the psychological perception of the operator.

\section{THEORETICAL BASIS OF FINANCIAL PRESSURE}

\section{A. Financial risk theory}

At present, there is no unified definition of financial pressure in academia, but financial pressure still is the part of the traditional category of financial risk management as the financial pressure is reflected in the financial management activities of enterprises. Financial pressures are brewing financial risks or financial crises, which are also necessary for financial risk management (Li Gang, 2016). Consequently, the research on financial pressure can date back to the risk management. 
In 1956, Snider put forward the concept of risk management, Modigliani(1958) and Miller(1961) put forward the famous MM theory to carry out research on the company's financial risks. In the early study of enterprise financial risks, the focus was mainly on the company's debt management. The rapid development of an enterprise depends on financing. The use of financing structure or financial leverage must be accompanied by different degrees of financial risks, thus the study of financial risk can be regarded as the prototype of the research on financial pressure of enterprises.(DuanHuayou etc. 2014). Research shows that enterprise risk management can reduce the cost of enterprises falling into financial difficulties (Neil Doherty, 2005), improve the rate of return on equity and corporate governance structure, which is of great advantage of solving the agency problem in corporate governance and enhance corporate value (Aggarwal, 1999).

\section{B. Financial report fraud related theories}

When it comes to "pressure", the first thing many people think of is the "pressure" in the "fraud triangle" theory. According to this theory, the occurrence of corporate fraud is composed of three elements: "pressure", "opportunity" and "excuse". The management of the enterprise is forced by "pressure" and has "opportunity" to engage in fraud, and has an appropriate "excuse" to extricate itself after being discovered. This kind of "pressure" may be operational or financial difficulties as well as the urgent demand for capital, which is the behavioral motivation of corporate fraudsters, including financial pressure, personal and social pressure. Among them, financial pressure is mainly reflected in the financial management activities of enterprises, which means the management's accounting manipulation due to the improvement of performance. This is to discuss the financial pressure faced by enterprises from the influence or consequence of financial pressure. This shows that financial pressure is brewing financial risks or financial crises for enterprises. Therefore, this is also the need for financial pressure evaluation and financial analysis.

\section{Signal transmission theory}

In the opinion of some scholars, external profit pressure is one of the significant manifestations of financial pressure. The external profit pressure arises from the deviation of profit forecast between analysts and management. As a kind of information difference and signal transmission, this deviation will have a direct impact on the investment and financing decision-making behavior of management, including mergers and acquisitions. Of course, it will also affect the judgment of external investors on the future profitability of enterprises and make them adopt corresponding merger and acquisition negotiation strategies to deal with these deviations (Lin Zhong Gao, 2015).

\section{Principal-agent theory}

On the one hand, the principal-agent relationship creates financial pressure. From the point of view of contract, the principal-agent contract between the operator and the owner is the dominant aspect (Gan Shengdao, 2016).

On the other hand, financial pressure will ease the agency problem to a certain degree. Jensen et al (1976) proposes that the use of debt can make up for the agency cost of external property rights. Issuing debt can reduce the scope of the manager's job consumption to give the manager the cash flow pressure to pay interest on a regular basis, which can enhance the governance efficiency more effectively than other financing methods.

\section{E. Resource dependence theory}

Resource dependence theory (Pfeffer \& Salancik, 1978; Kassinis \& Vafeas, 2006) emphasizes that enterprises need to obtain external resources for their business activities, but the risks brought about by enterprises' dependence on external input resources will result in the vulnerability, so as to answer what makes stakeholders have the ability to influence enterprises. It is proposed that enterprises' response to the pressure of stakeholders is due to their control over the key resources on which enterprises depend for survival.

\section{THE BASIC FRAMEWORK OF FINANCIAL PRESSURE}

\section{A. Sources of financial pressure}

At present, foreign scholars have not clearly put forward the concept of financial pressure, the existing literature is mainly analyzed is leading to the financial crisis and even bankruptcy factors. James R. Duncan (2002) suggests that 20 types of stress could result in earnings management, divided into external pressures, corporate culture and strategic pressures, personal factors. Among them, the external pressures are mainly analyst forecasts, investor expectations, bond market access, contractual restrictions, competition, etc. Corporate culture and strategic pressure mainly include merger attractive, management compensation, unrealistic plans and budgets, short-term goals, etc. Personal factors mainly include personal rewards, promotion, personal goals, risk preferences, etc.

However, some domestic scholars have clearly put forward the concept of financial pressure and discussed the sources of financial pressure. Duan Huayou et al (2014) believe that the sources of financial pressure include the government, competitors, suppliers, buyers, shareholders, creditors, employees and managers, which are formed by the internal and external environment of the enterprise acting on the financial activities of the enterprise. Duan Huayou et al (2014) also point out that the financial risks of small and mediumsized enterprises are often caused by external financing. The magnitude of financial pressure is closely related to the level of financial risks. Therefore, one of the researches focuses on the financial pressure of small and medium-sized enterprises is the analysis of financing structure. In addition, sometimes the financial pressure on small and medium-sized enterprises may be greater than the financial pressure after obtaining financing 
due to financing difficulties. Therefore, liquidity risk can also be regarded as one of the reasons that constitute the financial pressure of small and medium-sized enterprises.

Gan Shengdao (2016) believes that the fundamental source of financial pressure for enterprises is due to the asymmetric characteristics of income and expenses. Li Gang et al (2016) believe that the financial structure level of enterprises of different sizes is quite different, so that there is a huge gap between industries. The internal and external characteristics together act on the financial activities of enterprises to form financial pressure, such as frequent market economy volatility. Yang Bai et al (2016) believe that both social responsibility investment and research and development investment will bring financial pressure to enterprises, which impose heavy burden on enterprises.

\section{B. Classification of financial pressure}

As it has not been clearly put forward the concept of financial pressure, the research of foreign scholars mainly lays stress on the earnings management, profit pressure, debt pressure, capital market pressure, competition pressure, stakeholder pressure, etc. It can be said that the above aspects are specific classifications of financial pressure.

Some domestic scholars have discussed the classification of financial pressure. Wu Guoping and Ma Shi (2010) believe that typical financial pressures include debt service pressure caused by high debt ratio, cash flow pressure caused by insufficient cash flow, shell protection pressure, surplus protection pressure and signal pressure caused by declining profitability.

Gan Shengdao (2016) thinks that financial pressure can be divided into pressure side and compressed side from the perspective of subject and object. Performance can be divided into performance pressure and payment pressure. From the driver's point of view, it can be divided into the financial pressure caused by the controllable factor, the financial pressure caused by the uncontrollable factor.

\section{Measurement of financial pressure}

The existing scholars have different measures for it due to the non-unity and non-academic concept of financial pressure. Li Gang et al (2016) believe that financial pressure is mainly contributed by the long-term solvency, the ability of the enterprise to create profits for shareholders, and the profitmaking efficiency of the ratio of expenses to operating income. The three elements can be replaced by three indicators, which show different stress mentality. The difference in the transmission mechanism of the three elements determines their contribution proportion to financial pressure.

Wu Guoping et al (2010) divide financial pressure into debt service pressure, shell protection pressure, surplus protection pressure and cash flow pressure. Among them, current ratio, asset-liability ratio and ratio of current liabilities to total liabilities are used to measure debt service pressure, ST is used to measure shell protection pressure, loss is used to measure surplus protection pressure, and cash flow pressure is measured by operating cash flow/operating income, operating cash flow/short-term liabilities and operating cash flow/total liabilities. Subsequently, they studies the significance of the impact of these four types of financial pressures on listed companies' information disclosure violations. They finds that the impact of cash flow pressure is not significant

Professor Tang Guliang (2009), who first put forward the financial pressure measurement method, took the lead in proposing an innovative view after the 2008 financial crisis, introducing the financial pressure testing mechanism into industrial and commercial enterprises and constructing a risk "physical examination" mechanism for industrial and commercial enterprises. He advocates that taking the free cash flow (FCF) as an enterprise risk early warning test model. The stress test system can be divided into four modules according to FCF: Net operating cash flow, working capital, long-term investment and external financing (especially debt financing).

\section{THE IMPACT OF FINANCIAL PRESSURE}

At present, there are many literatures discussing the influence of financial pressure on enterprises, mainly in the aspects of investment and financing behavior, information disclosure behavior, operation behavior and performance of enterprises. In addition, the influence can be positive or negative. Duan Huayou et al. (2014) believe that financial pressure is not necessarily a negative impact, just as the dual nature of financial risk. Gan Shengdao (2016) also believes that the moderate financial pressure contributes to the enterprise development. Too large or too little financial pressure makes against the enterprise development.

\section{A. Impact of financial pressure on enterprise investment}

As a result of agency conflicts, information asymmetry and incomplete contracts, the investment level of enterprises make it easy for companies to invest at a level higher or lower than the best investment, arising in over-investment or underinvestment of inefficient investment. Many foreign scholars have studied the "hard constraints" of capital markets, such as the impact of financing constraints on enterprise investment (Myers and Maijluf, 1984; Fazzari et al., 1988; Stulz, 1990; Kaplan and Zingales, 1997). Some scholars have also learned the impact of "soft constraints" such as business expectations on inefficient investment. Arrfelt et al(2013) examines the impact of the gap between the actual performance of the enterprise and the operating expectations within the organization on the investment efficiency of the enterprise. Both "hard constraints" and "soft constraints" are manifestations of financial pressure.

Domestic scholars are also rich in research. Wang Jing et al (2014) takes listed companies in China's manufacturing industry from 2007 to 2012 as research samples, examined the mechanism of external profit pressure affecting insufficient investment. Moreover, they further explore the role of analyst concern and manager discretion in the regulation of the relationship between the two from the perspective of supervision and motivation. Chen Kexi et al (2015) find that analysts' earnings forecast pressure is positively related to under-investment and not related to over-investment. In addition, analysts' tracking and corporate governance 
association will negatively adjust the impact of earnings forecast pressure on under-investment behavior. The enhancement of external supervision and the broadening of access to resources can correct enterprises' inefficient investment behavior under the pressure of earnings forecast.

\section{B. Influence of financial pressure on enterprise financing}

Gan Shengdao (2016) believes that one of the key points of the study of financial pressure is the analysis of financing structure. Moreover, sometimes the financial pressure borne by small and medium-sized enterprises due to financing difficulties may be greater than the financial pressure after obtaining financing. At present, most researches lay stress on the analysis of financial risks and financial pressures caused by problems such as financing structure and channels. There is little literature on the impact of financial pressure on corporate fund-raising decisions.

\section{Impact of financial pressure on enterprise information disclosure}

Financial pressure is the direct cause of financial reporting fraud. Companies with greater financial pressure tend to disclose information in violation of the law ( $\mathrm{Wu}$ Guoping, et al. 2009, 2010). Zeng Yueming et al (2010) conducted a study on 74 listed companies that violated information disclosure rules during 2006-2009 in Shenzhen Stock Exchange. They believe that the profitability and debt-paying pressure of the companies take an important role in the violations of information disclosure rules.

\section{Impact of financial pressure on mergers and acquisitions}

By studying 216 mergers and acquisitions in the Yangtze River Delta region from 1997 to 2001, Li Jie (2007) finds that the financing pressure (the difference in financing costs due to differences in financing methods, which binds to the merger and acquisition behavior) can promote the performance of mergers and acquisitions.

Lin Zhonggao et al.(2016) conduct a study on China's nonfinancial listed companies in Shanghai and Shenzhen A shares from 2008 to 2013, and find that the greater the external profit pressure, the less inclined the companies are to merge, but the negative impact of this external profit pressure on merger and acquisition behavior will decrease with the improvement of the quality of internal control. Compared with enterprises with poor internal control, in enterprises with good internal control, the greater the external profit pressure, the greater the possibility of mergers and acquisitions. In addition, this relationship is more remarkable in listed companies with small executive power.

\section{CONCLUSION}

The above literature mainly discusses the financial pressure around the concept, theoretical basis, basic framework and influence. From this, it can see that the existing financial pressure is still an embryonic concept, and there has not been a recognized definition and explanation. In addition, its source and classification have not yet been systematically analyzed. The existing financial pressure evaluation is not systematic and does not comprehensively reflect the complex environment, interpersonal relationships and corresponding stress levels faced by enterprises in the operation process. Moreover, most of the measurement indicators stay in financial indicators that focus on financial results. Not paying attention to procedural indicators, not paying attention to the perceived financial pressures of enterprises will take time to ferment to lead to bad financial results, which may delay the time of early warning to enterprises. However, the existing financial pressure impact analysis is mostly the impact of a certain pressure point or a certain pressure on a certain aspect of the financial decisionmaking of an enterprise, and there is no systematic comprehensive analysis. Therefore, this paper hopes to provide corresponding support for the follow-up research base on the comprehensive summary of domestic and foreign literatures relevant to financial pressure of enterprises.

\section{REFERENCES}

[1] Andrew Benito and Garry Young. Financial Pressure and Balance Shee Adjustment by Firms [J]. Oxford Bulletin of Economics and Statistics, 2007: 581-602.

[2] Duan Huayou, Wangrui, Gan Shengdao. Mechanisms Analysis and Countermeasure Suggestions of Financial Pressure of Small and Medium-sized Enterprises[J]. Enterprise Economy, 2014(01):99-102.

[3] Gan Shengdao. Source and Control of Financial Pressure in Enterprises[J]. Friends of Accounting, 2016(9):20-22.

[4] James R. Duncan. Twenty Pressures to Manage Earnings[J]. CPA Journal, 2002,1-7.

[5] Katherine Guthrie, Jan Sokolowsky, Large Shareholders and the Pressure to Manage Earnings. [J]. Social Science Electronic Publishing, 2010, 16(3):302-319.

[6] Sandrine Kablan, Zied Ftiti, Khaled Guesmi. Commodity price cycles and financial pressures in African commodities exporters[J]. Emerging Markets Review, 2017(3): 215-231.

[7] Seema Miglani, Kamran Ahmed, Darren Henry. Voluntary corporate governance structure and financial distress: Evidence from Australia. Journal of Contemporary Accounting \& Economics[J]. 2015. 18-30.

[8] Stephen Nickell and Daphne Nicolitsas. How does financial pressure affect firms[J]. European Economic Review,1999(8): 1435-1456.

[9] Zhang, Y., and J. Gimeno. Earnings Pressure and Long-Term Corporate Governance: Can Long-Term-Oriented Investors and Managers Reduce the Quarterly Earnings Obsession? [J].Organization Science, 2016, 27:354-327. 